Working Paper in Economics No. 731

\title{
Cost of Power Outages for Manufacturing Firms in Ethiopia: A Stated Preference Study
}

Fredrik Carlsson, Eyoual Demeke, Peter Martinsson, and Tewodros Tesemma

Department of Economics, May 2018 


\title{
Cost of Power Outages for Manufacturing Firms in Ethiopia: A Stated Preference Study
}

Fredrik Carlsson, ${ }^{\#}$ Eyoual Demeke, ${ }^{+}$Peter Martinsson, ${ }^{*}$ and Tewodros Tesemma ${ }^{\dagger}$

\begin{abstract}
Having a reliable supply of electricity is essential for the operation of any firm. In most developing countries, however, electricity supply is highly unreliable. In this study, we estimate the cost of power outages for micro, small, and medium-sized enterprises in Addis Ababa, Ethiopia, using a stated preference survey. We find that the willingness to pay, and thus the cost of power outages, is substantial. The estimated willingness to pay for a reduction of one power outage corresponds to a tariff increase of 16 percent. The willingness to pay for reducing the average length of a power outage by one hour corresponds to a 33 percent increase. The compensating variation for a zero-outage situation corresponds to about three times the current electricity cost. There is, however, considerable heterogeneity in costs across sectors, firm sizes, and levels of electricity consumption. Policy makers could consider this observed heterogeneity when it comes to aspects such as where to invest to improve reliability and different types of electricity contracts.
\end{abstract}

Key Words: power outages, willingness to pay, choice experiment, Ethiopia

JEL Classification Numbers: D22, Q41

\footnotetext{
\# Department of Economics, University of Gothenburg, Box 640, SE-40530 Gothenburg, Sweden; Tel.: +46 31 786 5255; E-mail: fredrik.carlsson@economics.gu.se.

${ }^{+}$Department of Economics, University of Gothenburg, Box 640, SE-40530 Gothenburg, Sweden; Tel.: +46 31

786 1266; E-mail: eyoual.demeke@economics.gu.se.

* Department of Economics, University of Gothenburg, Box 640, SE-40530 Gothenburg, Sweden; Tel.: +46 31

786 5255; E-mail: peter.martinsson@economics.gu.se.

${ }^{\dagger}$ Department of Economics, University of Gothenburg, Box 640, SE-40530 Gothenburg, Sweden; Tel.: +46

31786 1266; E-mail: tewodros.tesemma@economics.gu.se.
} 


\section{Introduction}

The literature has documented abundant evidence of the indispensable importance of access to a reliable supply of electricity for economic growth (Andersen and Dalgaard, 2013; Dinkelman, 2011; Lipscomb et al., 2013). However, a sufficient and reliable supply of electricity is far from a reality in developing countries, and this is especially a problem in Sub-Saharan Africa. Frequent and lengthy outages characterize the electricity supply in this part of the world. Energy utilities in Sub-Saharan African countries are mainly publicly owned and usually opt to keep tariffs at a very low level to appease their urban constituency. The existing low electricity tariff rates make the costly investments required to improve supply economically unviable (Collier and Venables, 2012). While it is in customers' interest to pay low electricity tariffs, the question remains whether they would be willing to pay more for improvements in electricity service, particularly improvements in the reliability of supply. The objective of this paper is to measure the willingness to pay for improved reliability of electricity supply among one important group of customers in developing countries: micro, small, and medium-sized manufacturing enterprises in the capital of Ethiopia, Addis Ababa. We do this by using a stated preference method, and we focus on two broad aspects of power outages: the number of outages experienced in a month and the average length of a typical outage. In this study, we focus on firms in general and micro, small, and medium-sized manufacturing enterprises in particular, as these are economic agents that play a critical role in facilitating growth and creating employment opportunities in developing countries. Moreover, although the industry sector and residential consumers each account for 38 percent of electricity consumption in the country, the share of firms' consumption is expected to outstrip the share of consumption by households, making firms a point of interest.

Lack of reliable electricity service has been listed as a major obstacle preventing growth of firms in developing countries. In the 2017 World Bank Enterprise Survey (WBES) about 40 percent of firms in Sub-Saharan Africa stated that a shortage of electricity was a major constraint to the operations of the firm. ${ }^{1}$ The same survey also found that the average firm in Sub-Saharan Africa lost about 49 hours of economic activity in a typical month as a result of outages in 2015. Among Ethiopian firms, an average firm lost about 47 hours of economic activity per month as result of outages for the same period. The estimated incurred loss in terms of annual sales was about 7 percent for an average Ethiopian firm, while the 2017 WBES shows

\footnotetext{
${ }^{1}$ See http://www.enterprisesurveys.org/data/exploretopics/infrastructure\#sub-saharan-africa--7. The figure for firms in South Asia is around 46 percent for the same period.
} 
that the figure is about 8.2 percent for that of an average Sub-Saharan African firm. Allcott et al. (2016) report that electricity shortages reduced average output by about 5 percent for Indian manufacturing firms. However, the effect on productivity was small because of the possibility of storing most inputs during outages. Fisher-Vanden et al. (2015) find that an increase in electricity shortages has increased the unit cost of production of Chinese firms by about 8 percent.

To mitigate the negative impacts of power outages, firms have employed different strategies in developing countries, such as more flexible production and improved storage capacity. One obvious strategy is to invest in backup means of producing electricity, such as diesel generators. Backup diesel generators are costly, and it has been estimated that in Sub-Saharan Africa, selfgenerated electricity costs three to ten times as much as the electricity purchased from the grid (Eifert et al., 2008; Foster and Steinbuks, 2009). Even if a firm uses a generator, it would still face output loss, since substantial time and cost are associated with restarting machines after an outage, and the self-generated power might not be sufficient to run production at full capacity (Beenstock, 1991). Diesel generators also have negative impacts on air quality and noise levels. Moreover, a backup generator requires a large upfront investment cost at the time of purchase, since borrowing money for this type of investment is difficult if not impossible in most SubSaharan African countries. Thus, investment in a backup generator is most likely suboptimal, as it uses funds that could have been allocated to increasing production capacity (Reinikka and Svensson, 2002).

Long-term and sustainable solutions to improve the reliability of electricity supply in a country include investment in generation and distribution capacity together with a more flexible pricesetting scheme, such as peak-load pricing. In fact, one of the main reasons for the acute shortage of generation capacity in Africa is underpricing (Collier and Venables, 2012). Strategies for long-term reliability of electricity supply are particularly important in developing countries, where power outages are frequent events and there is a steady increase in demand. Large infrastructure programs such as improving and modernizing the grid require large investment costs, and this typically is out of reach for most utilities in Sub-Saharan Africa. One way to finance investments incrementally is through an increase in the electricity tariff. Implementing an increase in tariffs to finance investments is not easy, since the increase is done before investments are made. Thus, it is necessary to understand customers' willingness to pay for such improvements. This paper investigates micro, small, and medium-sized manufacturing enterprises' willingness to pay for improvements in the reliability of electricity supply. Since 
our focus is on the value of improvements that bring reliability to levels that do not exist today, we employ a stated preference method: choice experiment. Most of the research to date has used a revealed preference approach, where an indirect inference is made about the cost from actual averting expenditures of the firms, such as spending on backup generators. However, in many developing countries, firms' expenditures on equipment to cope with outages, such as backup generators, might be limited because of the credit market imperfection, raising the need to complement revealed preference approaches with stated preference.

Stated preference methods have primarily been used to measure the willingness to pay among households for improvements in the reliability of electricity supply (e.g., Carlsson and Martinsson, 2007; Meles, 2017; Moeltner and Layton, 2002; Oseni, 2017). Two studies that come close to the current study on enterprises are those of Morrison and Nalder (2009) and Ghosh et al. (2017). Morrison and Nalder (2009) analyze attitudes toward power among service and manufacturing businesses in Australia. However, the problems related to power outages there differ substantially from a developing country context, and the study focuses on a reduction of four outages per year, which corresponds to the total number of outages during a year. Ghosh et al. (2017) examine the willingness to pay of micro and small enterprises in India to reduce power outages using a contingent valuation study. In contrast, our study focuses on enterprises' valuation of a reliable electricity supply in Sub-Saharan Africa, which is an area prone to substantial problems with a reliable supply of electricity, and we shed light on two key attributes of power outages: frequency and duration.

Our results show that frequent and lengthy outages are causing substantial economic damages to small manufacturing firms in Ethiopia. In particular, we find that the total cost of outages for an average firm in our sample is about three times its current monthly electricity tariff. On the other hand, we also find that there is heterogeneity in the cost of outages, depending on the size, location, and sector of the firm.

\section{The survey and the econometric model}

\subsection{The choice experiment}

Both the contingent valuation method (e.g., Carlsson and Martinsson, 2007; Moeltner and Layton, 2002) and choice experiments (e.g., Carlsson and Martinsson, 2008; Ozbafli and Jenkins, 2016) are stated preference methods used to investigate the willingness to pay for improvements in the reliability of electricity supply. In this study, we use a choice experiment, 
since the objective is to investigate the marginal willingness to pay for changes in the two main characteristics related to power outages: duration and frequency.

The choice experiment was part of a large survey carried out with micro, small, and mediumsized manufacturing enterprises in Addis Ababa, Ethiopia, and the overall objective of the study was to investigate the energy transition and challenges faced by these enterprises. The survey was carried out in collaboration with the Environment and Climate Research Center (ECRC) at the Ethiopian Development Research Institute (EDRI), and the respondents were owners or managers of micro, small, and medium-sized enterprises. The questionnaire consisted of three parts: (i) general information about the firm, (ii) detailed questions related to firms, and (iii) the choice experiment. The final questionnaire was the result of several focus group studies followed by three pilot studies with 223 firms. $^{2}$ We sampled micro, small, and medium-sized manufacturing enterprises located in Addis Ababa in two stages. First, we randomly chose 1,000 of these enterprises from a list of more than 20,000 registered firms obtained from the Addis Ababa Trade Bureau and the Central Statistical Agency. Then we chose owners or managers of these enterprises to be the respondents in our study, because they are the ones who make important decisions when it comes to investments in production capacity for which decision on energy sources is crucial. ${ }^{3}$

In the introduction to the choice experiment, we first gave a general introduction to power outages and how utilities can reduce them by constructing new dams, upgrading the grid networks, improving the existing transmission and distribution lines, and also improving customer service in case of technical failures. This was followed by a description of the scenario (see Appendix A). The scenario focused on the firm owner's willingness to pay to reduce power outages by considering that the Ethiopian Electric Utility could improve reliability by making investments. The main effects of these investments would be a reduction in both the frequency and duration of power outages experienced by the firm. Each respondent was asked to choose the preferred alternative in four different choice sets. Each choice set included the status quothat is, the current situation - and two alternatives with improvements in terms of duration and frequency of power outages. The trade-off for the owner would be a reduction in these two parameters and increased electricity prices. To facilitate understanding, we also presented an example of a choice set to the respondents after we had read the scenario. The attributes and

\footnotetext{
${ }^{2}$ In addition, we conducted a trust experiment with 260 randomly selected survey participants.

${ }^{3}$ In a few cases where we could not reach the owner or manager, production managers and owners' spouses responded instead.
} 
levels used in the choice experiment are presented Table 1. The current situation (status quo) was obtained from the 2015 WBES for Ethiopia. In the third column of Table 1, we show the current situation during a typical month, which consists of 11 outages, on average, each lasting 5 hours, and an electricity price of 0.67 Ethiopian birr (ETB) ${ }^{4}$ per $\mathrm{kWh} .{ }^{5}$ The attribute levels in the fourth column present the frequency and duration of power outages after the improvements. We use a linear D-optimal procedure, in Stata, without any priors to generate a level balanced design with 12 choice sets. ${ }^{6}$ These 12 sets are then randomly blocked into three blocks with four choice sets in each.

Table 1. Attributes and levels in the choice experiment

\begin{tabular}{llcc}
\hline Attribute & Description & Current situation & Levels \\
\hline Frequency & $\begin{array}{l}\text { Number of outages in } \\
\text { a typical month }\end{array}$ & 11 & $5,7,9,10$ \\
Duration & $\begin{array}{l}\text { Length of a typical } \\
\text { outage in hours }\end{array}$ & 5 & $2,3,4,4.5$ \\
$\begin{array}{l}\text { Cost } \\
\text { (birr/kWh) }\end{array}$ & $\begin{array}{l}\text { Cost of electricity per } \\
\text { kWh }\end{array}$ & 0.67 & $0.8,0.94,1.07,1.21$ \\
\hline
\end{tabular}

The survey was conducted in the form of an interview, since some of the respondents might be illiterate. We gave the respondents a card depicting each choice set to make it easier for them to make their choices (see Figure 2 in Appendix A). To help the respondents better understand the cost attribute, we reminded them about their energy consumption from the last month and the equivalent monthly electricity expenditure for each alternative. A frequently discussed problem with stated preference studies is that they are hypothetical in nature, and thus they are not incentive compatible. A respondent can express a strong view in one direction without facing the direct consequences of her choices. To reduce this problem, Cummings and Taylor (1999) developed the idea of cheap talk scripts to circumvent the pitfalls associated with the hypothetical nature of the decisions, in their case protest answers in a contingent valuation study. The cheap talk script discusses the fact that there is a tendency for people to both over-

\footnotetext{
${ }^{4}$ Birr is the Ethiopian currency, and the exchange rate at the time of survey (April 2017) was US\$1 $=23.8$ ETB. A daily industrial worker's wage in Addis Ababa during the survey period was about 30-50 ETB.

${ }^{5}$ From the survey, we gathered information about the average frequency and duration of outages that micro, small, and medium-sized enterprises located in Addis Ababa face. Our survey also includes questions about the frequency and duration of outages that each firm experienced in the past 30 days. Albeit small differences, the information provided in the choice experiment on average is close to the average experienced outage. The utilities in Ethiopia use an increasing block price strategy. There are seven blocks. The lowest block covers consumption levels from 0 to $50 \mathrm{kWh}$ per month with a price of 0.27 birr per $\mathrm{kWh}$, while the highest block includes consumption levels above 500 $\mathrm{kWh}$ per month with a price of 0.6943 birr per $\mathrm{kWh}$. As shown in Table 2, most of the firms consume more than 500 $\mathrm{kWh}$ per month, motivating 0.67 birr per $\mathrm{kWh}$ as the average price in the current situation.

${ }^{6}$ We use the DCREATE command made available by Arne Risa Hole.
} 
and underestimate willingness to pay. Most stated preference surveys are concerned with overstatement of willingness to pay. However, in the case of power outages, there is also a risk that respondents might protest against the premise of the scenario, which is that they have to face higher costs in order to improve reliability (Carlsson et al., 2011).

\subsection{Econometric analysis}

In our analysis, we apply a random parameter logit model that allows for explicit modeling of unobserved heterogeneity. The utility each individual $q$ obtains from selecting alternative $i$ in choice set $t$ can be defined as

$$
U_{i q t}=\alpha_{i q}+\beta_{q} X_{i q t}+\varepsilon_{i q t}
$$

where $\alpha_{i q}$ is an alternative specific constant that captures individual $i$ 's intrinsic preference for the improvements, and $X_{i q t}$ stands for a vector of attributes. The vector of $\beta_{q}$ coefficients varies across individuals with a density function of $\mathrm{f}\left(\beta_{q} \mid \theta\right)$, where $\theta$ is the true parameter of the distribution. When we assume that the unobserved error term $\varepsilon_{i q t}$ is an independently and identically distributed (IID) type I extreme value, we obtain a random parameter logit (mixed logit) model. We use simulated maximum likelihood to estimate the model using 500 Halton draws. In the estimations, we use a triangular distribution for the random parameters of all attributes, with the upper endpoint set to zero and the lower endpoint to twice the size of the mean (Hensher and Greene, 2003). ${ }^{7}$ This restriction ensures that the cost, duration, and frequency attributes have a negative sign - that is, an increase in any of the attributes results in disutility. We have also explored a log-normal distribution as a way to restrict the sign of the coefficients, but as is commonly found in the literature, we have problems with convergence and fat tails of the distribution.

The analysis rests on the assumption that a respondent takes all the attributes and alternatives into consideration, and then chooses the preferred alternative in a choice set. However, studies reveal that respondents often use heuristics when making decisions and might not even take all the attributes into consideration (e.g., Carlsson et al., 2010; Hensher et al., 2005; Scarpa et al., 2009, 2012), usually referred as attribute nonattendance. This might arise for a number of reasons, such as unwillingness to pay for proposed improvements, less weight attached to some attributes, or simply cognitive fatigue. Whatever the reason might be, previous studies have

\footnotetext{
${ }^{7}$ If a normal distribution is assumed, then a subject is allowed to have both positive and negative effects on utility from an increase in any of the attributes, which is undesirable and unlikely.
} 
shown that failing to account for the fact that respondents do not consider an attribute when making a decision in the estimation could result in biased estimates. There are several approaches to deal with this, and here we use the responses to a follow-up question that explicitly asked individuals to indicate to what extent they have attended to each of the attributes while making their choices. The response alternatives were Always, In some but not all, and Not at all. For each attribute to which a respondent did not attend, we restrict the coefficient to zero for that particular attribute and respondent when estimating the model (Carlsson et al., 2010).

From the coefficient estimates, we then estimate marginal willingness to pay for the two attributes, which is calculated as the ratio between the attribute coefficient and the price coefficient. If we view these estimates as representative of the whole sample, we make the implicit assumption that the nonattendance is due to a decision heuristic and not a proper reflection of an actual preference. In other words, those that did not attend to the cost attribute still have a preference for the cost attribute but opted not to attend to this attribute when responding in the experiment. The best available information we have about the preference for the nonattended attributes is the preferences among those that actually did attend to the attribute. Clearly, if attendance is correlated with the strength of the preference, this is not an appropriate assumption.

\section{Results}

\subsection{Descriptive statistics}

In Table 2, we report descriptive statistics of the firms and their owners included in our sample. We interviewed owners or managers of 1,000 firms operating in different part of Addis Ababa, and after dropping observations with missing information on some socioeconomic aspects, we are left with a final working sample of 947 firms. 
Table 2. Descriptive statistics

\begin{tabular}{lccccc}
\hline Variable & Obs. & Mean & Std. dev. & Min & Max \\
\hline Firm characteristics & & & & & \\
Firm age in years & 941 & 6.26 & 5.85 & 1 & 59 \\
Number of employees & 947 & 9.93 & 10.60 & 1 & 70 \\
Monthly sales (in 1,000 ETB) & 933 & 145 & 195 & 0 & 5,877 \\
Own diesel generator (= 1 if yes) & 947 & 0.14 & 0.35 & 0 & 1 \\
Electricity consumption (kWh per month) & 947 & 990 & 2,974 & 11 & 57,971 \\
Industry zone location (= 1 if yes) & 947 & 0.30 & 0.46 & 0 & 1 \\
Monthly profit lost due to outages (in ETB) & 914 & 4,683 & 12,816 & 0 & 200,000 \\
Cost due to outages (per month in ETB) & 934 & 2,807 & 7,314 & 0 & 100,000 \\
Adjust operation time due to outages (=1 if & 944 & & & & \\
yes) & & 0.49 & 0.50 & 0 & 1 \\
Owner characteristics & & & & & \\
Age of the owner (in years) & 937 & 39.39 & 10.55 & 21 & 76 \\
Male (= 1 if owner is male) & 942 & 0.80 & 0.40 & 0 & 1 \\
At least college diploma (=1 if yes) & 947 & 0.14 & 0.34 & 0 & 1 \\
Business experience in years & 936 & 7.82 & 6.84 & 1 & 59 \\
Trust in electric utility (0 if low and 10 if high) & 947 & 4.89 & 2.53 & 0 & 10 \\
\hline
\end{tabular}

An average firm in our sample has been in operation for little more than six years and has 10 employees. The average monthly revenue is 145,000 ETB. About 14 percent of firms own backup generators that are used during power outages, and the average electricity consumption is $990 \mathrm{kWh}$ per month. In addition, 30 percent of the firms are located in industry zones. These are industry clusters built and owned by the government with the purpose of supporting micro, small, and medium-sized manufacturing enterprises. The average age of an owner or manager of a firm is 39 years, and a large majority of the owners are male. Only 14 percent of the owners or managers have at least a college diploma. On average, owners and managers in our sample have business experience as an owner or manager extending to eight years. When asked to rate their trust in the electric utility on a scale ranging from 0 (no trust at all) to 10 (have complete trust), owners or managers state a rather low level of trust, with an average of less than 5 . The average loss in profits due to outages is 4,683 ETB, and firms on average incur 2,807 ETB as extra costs of outages on items such as fuel and maintenance expenses of generators and labor costs. Comparing the costs incurred in terms of monthly sales, on average, firms lose 14 percent of their monthly sales. About 49 percent of the firms in our sample have been forced to adjust their operation times, and 14 percent of firms report to own a diesel generator that is used during power outages.

Figure 1 shows the self-reported frequency and average duration of typical outages. The average number of outages is about 13 per month. This is comparable to the frequency of outages in the 
status quo alternative of our choice experiment, with 11 outages. In terms of duration, an overwhelming majority of firms in our sample (75 percent) experience outages lasting more than 2 hours.

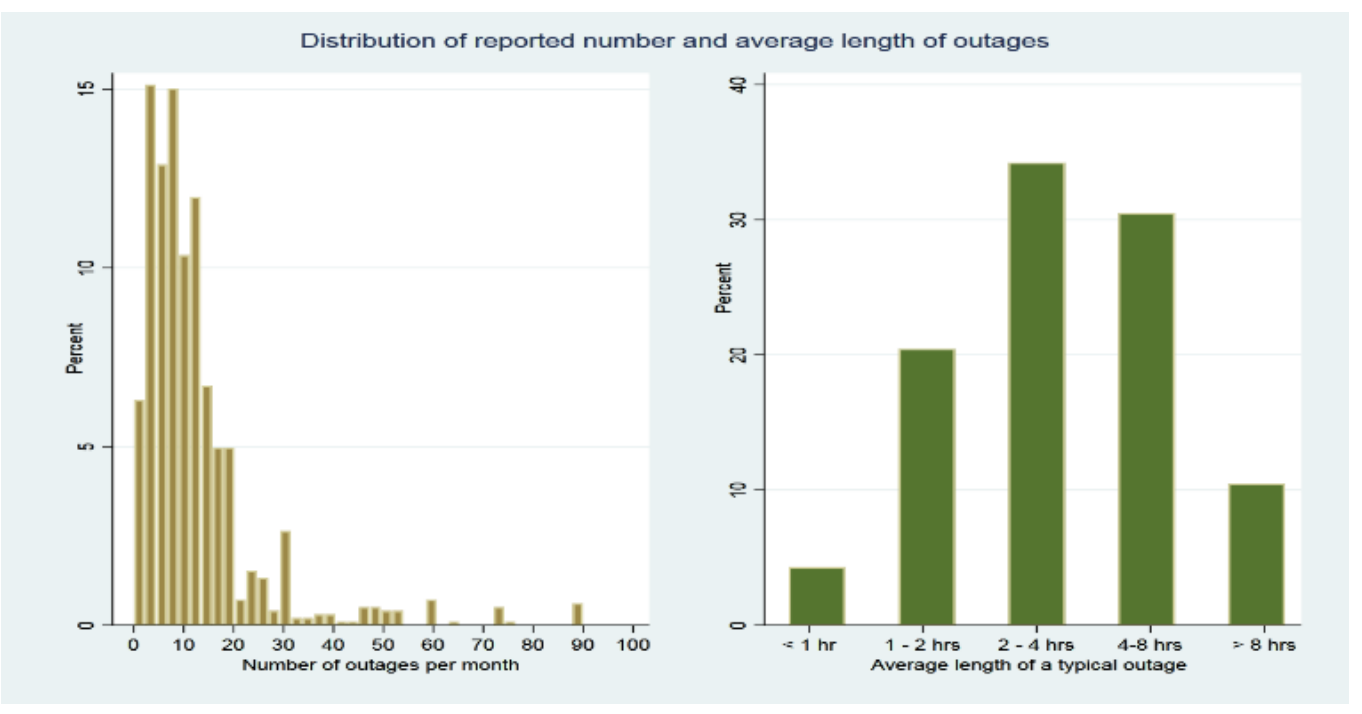

Figure 1. Distribution of self-reported frequency and duration of outages

\subsection{Econometric analysis}

\subsubsection{Main result}

We begin by looking at the stated nonattendance, based on the follow-up question asking respondents to state to what extent they had attended to each of the attributes while making their choices. Table 3 presents a summary of the distribution of nonattendance for each of the attributes.

Table 3. Attendance to attributes $(n=947)$

\begin{tabular}{lccc}
\hline Attendance & Frequency & Duration & Cost \\
\hline Yes & $94 \%$ & $93 \%$ & $65 \%$ \\
No & $6 \%$ & $7 \%$ & $35 \%$ \\
\hline
\end{tabular}

A large majority of the respondents stated that they had attended to both the frequency and the duration attributes, but only 65 percent had attended to the cost attribute. While this is common in the literature (Carlsson et al., 2010), it points to the importance of considering this issue in the analyses. We estimate a probit model where the dependent variable is equal to one if any of the attributes were not attended to, and otherwise zero. Results are presented in Table B1 in Appendix B. The analysis shows that the likelihood of nonattendance is higher among larger firms if the firm has adjusted its operation times due to outages, if the firm incurs high costs of 
outages, and if the owner has a low level of trust in the electric utility. This is an indication of a focus on the outage attribute among firms that suffer more from outages.

Our main analysis is based on a regression model where we restrict the corresponding coefficient to zero for those respondents that stated that they did not attend to the attribute. Based on this model, we estimate marginal willingness to pay for the attributes. Our interpretation is that this is the marginal willingness to pay for the whole sample, including those that did not attend to the cost attribute. As we have discussed, the implicit assumptions are thus that those not attending to the cost attribute do not have zero marginal utility of money and that we use the estimate for those attending to the attribute to infer the marginal utility of money for those not attending to the cost attribute. In Table 4, we present the results of the random parameter logit model with restricted triangular distributions using observations from 947 firms.

Table 4. Results of the random parameter logit model with triangular distribution

\begin{tabular}{lcc}
\hline & Coefficient & Coeff. std. dev. \\
\cline { 2 - 3 } ASC (= 1 for improved alternative) & 0.040 & $0.717^{* * *}$ \\
& $(0.055)$ & $(0.094)$ \\
Frequency & $-0.774^{* * * *}$ & $0.774^{* * *}$ \\
& $(0.035)$ & $(0.035)$ \\
Duration & $-1.570^{* * *}$ & $1.570^{* * *}$ \\
& $(0.071)$ & $(0.071)$ \\
Cost & $-7.153^{* * *}$ & $7.153^{* * *}$ \\
& $(0.383)$ & $(0.383)$ \\
\hline Log-likelihood & $-2,842.45$ & \\
Pseudo $R^{2}$ & 0.316 & \\
Observations & 3,788 & \\
Subjects & 947 & \\
\hline Note: Standard errors in parentheses. ${ }^{* * *}, * *, *$ denote significance at $1 \%, 5 \%$, and $10 \%$ levels, respectively.
\end{tabular}

As expected, all the attribute coefficients are negative and statistically significant. Moreover, all the estimated standard deviations of the coefficients are statistically significant, indicating that the model captures unobserved heterogeneity among the respondents. The alternative specific constant (ASC) is a dummy variable for the alternatives with improvements. The fact that the ASC is not statistically significant indicates that on average, respondents did not just choose one of the improved alternatives or chose to stick with the current situation without considering the levels of the attributes in each of the alternatives. 
Our main interest lies in estimating the marginal willingness to pay for the two outage attributes: frequency and duration. The marginal willingness to pay for both attributes is presented in Table 5.

Table 5. Marginal WTP estimates in ETB per $\mathrm{kWh} / \mathrm{month}$ and total cost of outages in ETB/month

\begin{tabular}{lccc}
\hline Attributes & $\begin{array}{c}\text { Marginal WTP } \\
(\text { ETB per kWh) }\end{array}$ & $\begin{array}{c}\text { Marginal WTP (ETB } \\
\text { per month) }\end{array}$ & $\begin{array}{c}\text { Total cost of outages } \\
\text { (ETB/month) }\end{array}$ \\
\hline Frequency & $0.11(0.12-0.10)$ & 109 & 1,198 \\
Duration & $0.22(0.24-0.20)$ & 218 & 1,089 \\
\hline
\end{tabular}

Note: Standard errors estimated using the Delta method.

On average, firms are willing to pay $0.11 \mathrm{ETB}$ per $\mathrm{kWh}$ for a one-unit reduction in the number of outages they face per month. This amount corresponds to about 16 percent of the current price of a kWh of electricity. Regarding the duration attribute, on average, firms are willing to pay $0.22 \mathrm{ETB}$ per kWh to reduce the length of an average outage by one hour. Compared with the current electricity tariff, this amounts to 33 percent of the electricity price per $\mathrm{kWh} .{ }^{8} \mathrm{We}$ then calculate the marginal WTP in ETB per month for each attribute by the average monthly electricity consumption of firms in our sample. The results from this analysis are presented in column 3. We also estimate willingness to pay as a total outage cost per month. This is done by multiplying the marginal WTP estimate for outages by the total number of outages and the marginal WTP estimate for duration by the average duration, and then adding the overall preference for a change as indicated by the alternative specific constant divided by the cost attribute. This estimate is then multiplied by the average monthly electricity consumption (990 $\mathrm{kWh} /$ month) so that we have a measure in ETB per month. The total monthly cost of outages for an average firm is 2,293 ETB (US\$96). This implies a threefold increase from the firms' average current monthly electricity bill. The cost of outages amounts to 3 percent of the firm's monthly sales, or about 61 percent of the average monthly cost from using backup generators.

\subsubsection{Observed heterogeneity in preferences}

So far, we have focused on the sample averages. This provides only a limited insight to inform policy makers on how to prioritize investments in the energy sector. It is indeed important for policy makers to know and understand heterogeneity, if there is any, in cost of outages

\footnotetext{
${ }^{8}$ In Tables B2 and B3 in Appendix B, we present the corresponding estimates for a random parameter logit (RPL) model without considering stated nonattendance. These estimates are slightly higher than the estimates when considering attribute nonattendance in the estimation procedure.
} 
depending on different characteristics of firms. To shed some light on this, we investigate three important aspects of firm characteristics - location, size, and type of sector-by estimating separate models for different groups of firms.

\subsubsection{Location}

Firms in our sample can be divided into two broad categories based on the setup of their locations: industry clusters and nonindustry clusters. Industry clusters are zones set up by the government with the aim of providing working premises and necessary infrastructure for manufacturing firms. They are also intended to facilitate technological spillovers among firms and spur innovation. From the point of view of addressing power outages, the location of firms would be one aspect that policy makers could consider to prioritize investments. The estimated models for industry and nonindustry zone firms are presented in Table B4 in Appendix B, and the corresponding MWTP estimates are presented in Table 6.

Table 6. MWTP for frequency and duration attributes based on location of firms

\begin{tabular}{lcc}
\hline \hline Attributes & Industry cluster & Nonindustry cluster \\
\hline MWTP in birr per $k W h$ & & \\
Frequency & $0.13(0.11-0.15)$ & $0.10(0.09-0.11)$ \\
Duration & $0.23(0.20-0.27)$ & $0.21(0.20-0.23)$ \\
$M W T P$ in birr per month & & \\
Frequency & 113 & 104 \\
Duration & 200 & 219 \\
\hline
\end{tabular}

Note: Standard errors in parentheses.

As can be seen in the top panel of the table, firms located inside an industry cluster have on average higher MWTP per kWh for both attributes. The MWTP of reducing frequency of an outage by one unit is 0.13 birr for the industry cluster group but only about 0.10 birr for the nonindustry cluster group. Using z-tests, we can reject the hypothesis of equal MWTP values between the two groups for the frequency attribute ( $p$-values $=0.002)$, while we fail to reject the hypothesis for the duration attribute $(p=0.344)$.

Based on the estimated MWTP values and current monthly electricity use, we can estimate the MWTP per month for the two groups as well. The bottom panel of Table 6 shows that for the frequency attribute, the MWTP per month is higher for firms inside the industry cluster than for those outside the industry cluster, while it is the opposite for the duration attribute. Thus, there are very small differences between the two types of firm locations from an economic point of view. It could be that firms located in industry clusters are enjoying better electricity services 
and hence their cost of outages is not as large, even though these firms are different in other respects. This is in fact true, as firms in industry clusters report suffering fewer outages per month than those outside industry clusters. ${ }^{9}$

\subsubsection{Firm size}

Firm size is another aspect that might correlate with the cost of outages, and this criterion could be important for policy makers to use when planning investments. Micro firms (up to 5 employees), for example, might not have the financial resources to invest in backup generators, whereas small (6-10 employees) and medium-sized (11-100 employees) firms are more likely to have financial resources. On the other hand, small and medium-sized firms might rely heavily on electricity service such that even the use of backup generators would not satisfy their needs during power outages. In this case, these groups might suffer higher costs of outages than micro firms. The estimated models for the three groups are presented in Table B5 in Appendix B, and the corresponding MWTP estimates are presented in Table 7.

Table 7. MWTP estimates by size of firms

\begin{tabular}{lccc}
\hline Attributes & Micro & Small & Medium \\
\hline MWTP in birr per $k W h$ & $0.10(0.09-0.11)$ & $0.13(0.11-0.15)$ & $0.11(0.10-0.13)$ \\
Frequency & $0.19(0.17-0.21)$ & $0.26(0.22-0.31)$ & $0.23(0.20-0.26)$ \\
Duration & & & \\
$M W T P$ in birr per month & 53 & 94 & 212 \\
Frequency & 101 & 187 & 444 \\
Duration & & & \\
\hline
\end{tabular}

The top panel of the table shows that small firms have the highest MWTP in birr per kWh for both attributes, while micro firms have the lowest MWTP for both attributes. We tested the differences using $t$-statistics. For the duration attribute, the MWTP differences are statistically significant at 5 percent, with the exception of the comparison between small and medium-sized enterprises. The differences in MWTP for the frequency attribute are statistically significant only between micro and small enterprises.

\footnotetext{
${ }^{9}$ The $t$-test for mean comparison of frequency of outages shows that firms in industry clusters face 1.5 fewer outages than those outside clusters, and the difference is statistically significant at the 1 percent level. Similarly, mean ownership of generators is 16 percent among firms outside industry zones, whereas it is just 8 percent among those inside, and the difference is statistically significant at the 1 percent level.
} 
The bottom panel of the table shows an estimate of the MWTP in birr per month for each firm size group. As these values are obtained by multiplying the MWTP in birr per kWh by the monthly average electricity consumption of each group, we observe a different pattern when we compare across the groups. The micro firms have the lowest MWTP in birr per month for both attributes compared with the other two groups. On the other hand, the medium-sized firms have the highest MWTP in birr per month for both attributes. These differences in the average electricity consumption across the groups are the main driving force behind the observed pattern in the MWTP in birr per month figures. Thus, the outage costs are considerably higher the larger the firm is.

\subsubsection{Sector}

The production process and the reliance on electricity might be different in different sectors, which in turn could affect the outage costs. We therefore divide our sample into five sectors based on definitions from the Central Statistical Agency of Ethiopia: food and beverage; textile, garment, and leather; metal-working workshop; nonmetallic minerals and construction; and plastic, rubber, and machinery. Results of the random parameter logit models are presented in Table B6 in Appendix B, and the MWTP values are presented in Table 8.

Table 8. Marginal willingness to pay for the attributes by sector measured in birr/kWh

\begin{tabular}{lcccc}
\hline \hline & \multicolumn{2}{c}{ MWTP in birr per kWh } & \multicolumn{2}{c}{ MWTP in birr per month } \\
\cline { 2 - 5 } & Frequency & Duration & Frequency & Duration \\
\hline Food and beverage & 0.08 & 0.17 & 200 & 425 \\
Textile, garment, and leather & $(0.10-0.07)$ & $(0.19-0.14)$ & & \\
& 0.11 & 0.21 & 38 & 72 \\
Metal-working workshop & $(0.13-0.09)$ & $(0.25-0.17)$ & & 129 \\
Nonmetallic minerals and & 0.11 & 0.24 & 59 & 212 \\
construction & $(0.12-0.10)$ & $(0.28-0.21)$ & & \multirow{2}{*}{0.26} \\
Plastic, rubber, and & 0.14 & $(0.32-0.20)$ & 114 & 237 \\
machinery & $(0.17-0.10)$ & 0.22 & 129 & 29 \\
\hline
\end{tabular}

As we have done above, here we also estimate both the MWTP in birr per kWh and the MWTP in birr per month for each of the sectors. Column 2 shows that firms in the nonmetallic minerals and construction sector have the highest MWTP per kWh for both the frequency and duration attributes. Their MWTP per kWh corresponds to a 20 percent and 38 percent increase in the electricity price to reduce the average number of outages from 11 to 10 in a month and to reduce 
the average duration of an outage from 5 to 4 hours. Firms in the food and beverage sector have the lowest MWTP per kWh for improved electricity service.

In column 3, we show the MWTP in birr per month for each of the sectors, where we multiply the MWTP per kWh values in column 2 by the average monthly electricity consumption of the sectors. The results show that the food and beverage sector has the highest MWTP in birr per month for both attributes. The textile, garment, and leather sector is found to have the lowest MWTP in birr per month for both the frequency and duration attributes.

\section{Conclusions}

Access to a reliable supply of electricity is considered an important component of economic development. In many developing countries, firms are suffering from power outages that are both frequent and of long duration, which makes it difficult to plan and undertake production activities. Thus, understanding the cost for firms associated with an unreliable electricity supply is important especially for policy makers who plan investment in the energy sector.

Previous studies have used different approaches to estimate the cost of outages for firms as well as to investigate which coping mechanisms firms employ. Most of the research to date has used a revealed preference approach.. However, in many developing countries, firms' expenditures on equipment to cope with outages, such as backup generators, might be limited because of the credit market imperfection, raising the need to complement revealed preference approaches with stated preference. To date, only a handful of studies have used a stated preference approach. These include Morrison and Nalder (2009) and Ghosh et al. (2017), who attempted to estimate the cost of outages in Australia and India, respectively. A detailed and comprehensive analysis of the issue is lacking for Sub-Saharan Africa, where unreliable electricity service is among the major reasons preventing economic growth.

This paper contributes to this issue by estimating the cost of outages for micro, small, and medium-sized manufacturing enterprises located in Addis Ababa, Ethiopia. To this end, we conducted a choice experiment and estimated a random parameter logit model. The proposed improvement of the service applied in our choice experiment included two different components: the number of outages experienced in a month and the average length of a typical outage. We find that manufacturing firms in Addis Ababa incur substantial costs due to power outages. An average firm's total cost of outages is 2,293 ETB (US\$96) per month, which 
corresponds to a threefold increase from the firms' average current monthly electricity bill. The cost of outages also amounts to 3 percent of the firm's monthly sales, which equates to about 61 percent of the average monthly cost from using backup generators. Our results indicate the existence of significant heterogeneity in terms of size, location (whether the firm is inside an industry cluster), and sector in which the firm operates. These findings have important policy implications. Given the significant cost of outages and the firms' willingness to pay to avoid outages, increasing tariff rates is one potential avenue to achieve the financial investment necessary to provide reliable electricity. In addition, the observed heterogeneity affords the opportunity to prioritize the investment in some aspects, such as by considering location and focusing on industry clusters.

\section{Acknowledgments}

We have received valuable comments from Yonas Alem and seminar participants at the University of Gothenburg. We gratefully acknowledge financial support from the Environment and Climate Research Center (ECRC) at the Ethiopian Development Research Institute (EDRI) and the Swedish International Development Cooperation Agency (Sida) through their support to the Environmental Economics Unit at the Department of Economics, University of Gothenburg. 


\section{Appendix A. Choice Experiment Scenario}

Following is the description of the scenario that we presented to respondents in our choice experiment:

Now I will ask you questions about your company's willingness to pay to reduce power outages. As you might know, there are discussions above improving electricity service in the country by making necessary investments. The Ethiopian Electric Utility is considering investments such as the construction of new dams, upgrading of the grid networks, improving the existing transmission and distribution lines, and also improving customer service in case of technical failures. It is believed that these investments will reduce both the frequency and duration of unplanned power outages observed during your operation hours. These investments are costly and would result in increased electricity prices.

In order to obtain information about what customers think about outages, we are going to ask you a number of questions. In particular, we will ask you to make choices among different alternatives. Each alternative will describe the frequency and average length of outages in a typical month and the cost of electricity in birr per kWh. Let me show you an example. [Show example card.]

\begin{tabular}{lccc}
\hline & $\begin{array}{c}\text { Alternative A } \\
\text { (no action) }\end{array}$ & Alternative B & Alternative C \\
Frequency & 11 outages & 11 outages & 10 outages \\
Length & 5 hours & 4.5 hours & 5 hours \\
Cost (in birr/kWh) & 0.67 & 0.80 & 0.94 \\
\hline Reminder: your energy use $(\mathrm{kWh})$ & $\ldots \ldots \ldots \ldots$ & & \\
\hline Your choice & & \\
\hline
\end{tabular}

Alternative A describes the situation if no action is taken. If no improvements are made, then it is predicted that on average, you will face 11 power outages per month, with an average length of 5 hours each. Cost of electricity will be the same as today.

In alternatives $\mathrm{B}$ and $\mathrm{C}$, investments are made to affect power outages, and this also means that the cost of electricity increases. To help you to understand what the cost increase implies, we also remind you of your current electricity use.

In alternative $\mathrm{B}$, there is no change in the number of outages, but the average length of each outage is reduced to 4.5 hours. At the same time, the electricity price increases to 0.80 birr per 
kilowatt-hour. In alternative $\mathrm{C}$, there is instead a reduction in the number of outages to 10 per month, while the average length of an outage is the same as the current situation. The electricity price increases to 0.94 birr per kilowatt-hour.

We would like to know which of these alternatives you prefer. We will ask you to make four such choices. Please bear in mind that the choice you make only affects the frequency and length of the power outages and the electricity tariff; everything else remains as it is today. The government is committed to ensure that the money obtained from the tariff increments is used solely to improve the electricity service.

Experience from previous studies indicates that people often state their unwillingness to pay to improve the current state not because they do not want improvements, but for other reasons. We believe that this can sometimes be because of a belief that they have a right to uninterrupted electricity or that the resources would not be used for their intended purpose. However, we ask that you not think this way when choosing among the alternatives. You might have other reasons to respond this way. If you have any thoughts about this, please state the reasons following your choices.

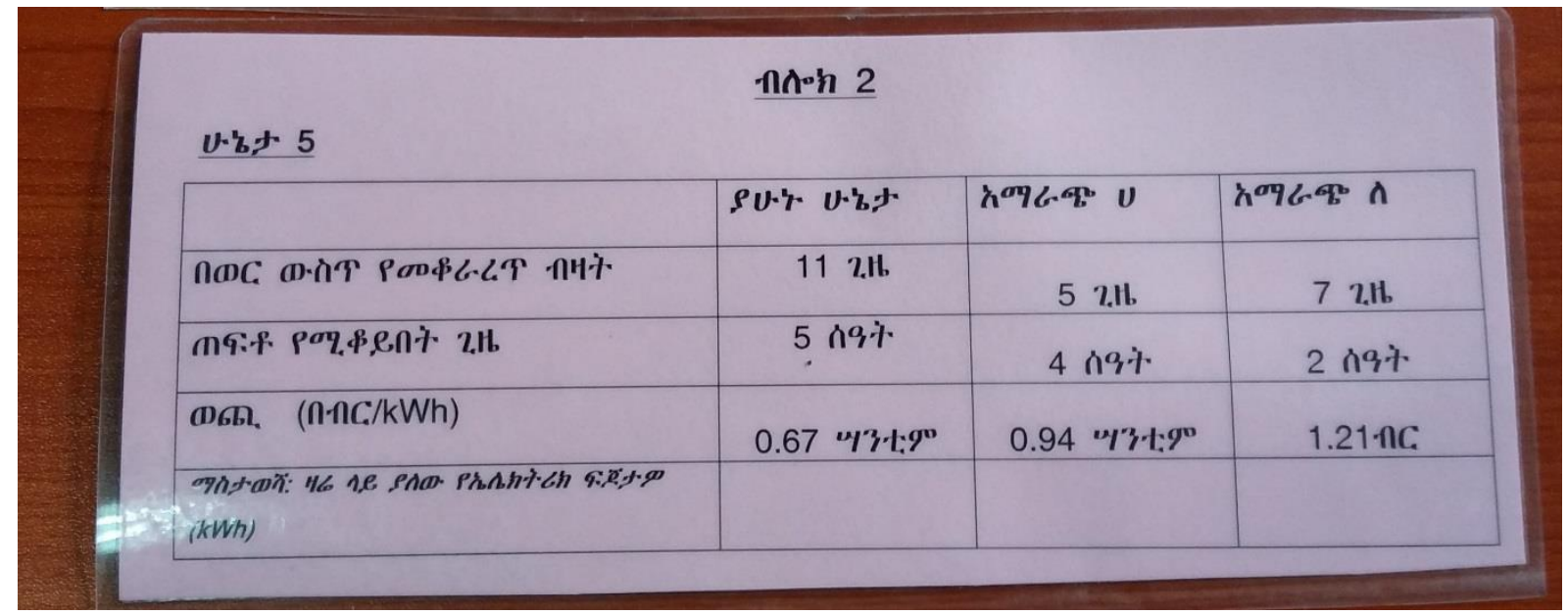

Figure 2. Example of choice card shown to respondents 


\section{Appendix B. Supplementary regressions}

Table B1. Marginal effects of probit regression of nonattendance to attributes, dependent variable equal to 1 if attribute was not attended to

\begin{tabular}{|c|c|}
\hline Variables & \\
\hline Frequency of outages $(1,000)$ & $\begin{array}{r}-0.075 \\
(0.03)\end{array}$ \\
\hline $1=$ adjust operation time & $\begin{array}{r}0.134 \\
(1.53)\end{array}$ \\
\hline Cost of outages (in 100,000 birr) & $\begin{array}{r}0.473 \\
(0.69)\end{array}$ \\
\hline Satisfaction with current service & $\begin{array}{l}-0.103 \\
(2.33)^{* *}\end{array}$ \\
\hline Monthly electricity use (in $100,000 \mathrm{kWh}$ ) & $\begin{array}{r}-1.969 \\
(1.16)\end{array}$ \\
\hline 1 = located inside industry cluster & $\begin{array}{r}-0.076 \\
(0.79)\end{array}$ \\
\hline Firm age (in years) & $\begin{array}{r}-0.006 \\
(0.76)\end{array}$ \\
\hline Number of employees (100) & $\begin{array}{r}0.945 \\
(1.84)^{*}\end{array}$ \\
\hline Monthly sales (in $1,000,000$ birr) & $\begin{array}{r}-0.007 \\
(0.05)\end{array}$ \\
\hline $1=$ own backup generator & $\begin{array}{r}-0.104 \\
(0.80)\end{array}$ \\
\hline Owner's age & $\begin{array}{r}-0.007 \\
(1.52)\end{array}$ \\
\hline $1=$ at least college diploma & $\begin{array}{c}0.134 \\
(1.02)\end{array}$ \\
\hline $1=$ male & $\begin{array}{r}0.239 \\
(2.13)^{* *}\end{array}$ \\
\hline Pseudo $R^{2}$ & 0.021 \\
\hline$N$ & 895 \\
\hline
\end{tabular}


Table B2. RPL model for electricity reliability attributes without consideration of nonattendance

\begin{tabular}{|c|c|c|c|}
\hline \multirow{3}{*}{\multicolumn{2}{|c|}{$\operatorname{ASC}(=1$ if the new alternative is chosen $)$}} & Coefficient & Std. dev. \\
\hline & & 0.063 & $0.709^{* * *}$ \\
\hline & & $(0.054)$ & $(0.091)$ \\
\hline \multirow{2}{*}{\multicolumn{2}{|c|}{ Frequency }} & $-0.753^{* * *}$ & $0.753^{* * *}$ \\
\hline & & $(0.037)$ & $(0.037)$ \\
\hline \multirow{2}{*}{\multicolumn{2}{|c|}{ Duration }} & $-1.572^{* * *}$ & $1.572^{* * *}$ \\
\hline & & $(0.078)$ & $(0.078)$ \\
\hline \multicolumn{2}{|l|}{ Cost } & $\begin{array}{c}-5.692^{* * *} \\
(0.344)\end{array}$ & $\begin{array}{c}5.692^{* * * *} \\
(0.344)\end{array}$ \\
\hline \multirow{4}{*}{\multicolumn{2}{|c|}{$\begin{array}{l}\text { Log-likelihood } \\
\text { Pseudo } R^{2} \\
\text { Observations } \\
\text { Subjects }\end{array}$}} & $-3,118.00$ & \\
\hline & & 0.251 & \\
\hline & & 3,788 & \\
\hline & & 947 & \\
\hline \multicolumn{4}{|c|}{ Note: Standard errors in parentheses. ${ }^{* * *}, * *, *$ denote significance at $1 \%, 5 \%$, and $10 \%$ levels, respectively. } \\
\hline \multicolumn{4}{|c|}{ Table B3. Marginal WTP estimates from RPL model without consideration of nonattendance } \\
\hline Attributes & RPL (triangular dist.) & Tot & $\begin{array}{l}\text { cost of outages } \\
\text { ETB/month) }\end{array}$ \\
\hline Frequency & $0.13(0.14-0.12)$ & & 129 \\
\hline Duration & $0.28(0.28-0.26)$ & & 277 \\
\hline
\end{tabular}

Table B4. Random parameter logit model for different firm locations

\begin{tabular}{lcccc}
\hline \hline \multirow{2}{*}{ Variable } & \multicolumn{2}{c}{ Inside industry zone } & \multicolumn{2}{c}{ Outside industry zone } \\
\cline { 2 - 5 } ASC & Coeff. & Std. dev. & Coeff. & Std. dev. \\
\hline \multirow{3}{*}{ Frequency } & 0.135 & $0.865^{* * *}$ & 0.007 & $0.617^{* * *}$ \\
& $(0.106)$ & $(0.163)$ & $(0.063)$ & $(0.120)$ \\
Duration & $-0.822^{* * *}$ & $0.822^{* * *}$ & $-0.741^{* * *}$ & $-0.741^{* * *}$ \\
& $(0 . .069)$ & $(0.069)$ & $(0.041)$ & $(0.041)$ \\
Cost & $-1.446^{* * *}$ & $1.446^{* * *}$ & $-1.610^{* * *}$ & $-1.610^{* * *}$ \\
& $(0.122)$ & $(0.122)$ & $(0.086)$ & $(0.086)$ \\
& $-6.195^{* * *}$ & $6.195^{* * *}$ & $-7.497^{* * *}$ & $-7.497^{* * *}$ \\
Log-likelihood & $(0.653)$ & $(0.653)$ & $(0.465)$ & $(0.465)$ \\
Pseudo $R^{2}$ & -821.738 & \multicolumn{3}{c}{$-2,012.696$} \\
Observations & 0.33 & 0.31 & \\
Subjects & 1,124 & \multicolumn{4}{c}{6664} \\
Standard errors in parentheses. ${ }^{* * *}, * *, *$ denote significance at $1 \%, 5 \%$, and $10 \%$ levels, respectively.
\end{tabular}


Table B5. Random parameter logit model for different firm sizes

\begin{tabular}{lcccccc}
\hline \hline & \multicolumn{2}{c}{ Micro } & \multicolumn{2}{c}{ Small } & \multicolumn{2}{c}{ Medium } \\
\cline { 2 - 7 } & Coeff. & Std. dev. & Coeff. & Std. dev. & Coeff. & Std. dev. \\
\hline ASC & -0.013 & 0.622 & -0.093 & 0.674 & $0.232^{* *}$ & $0.811^{* * *}$ \\
& $(0.076)$ & $(0.138)$ & $(0.113)$ & $(0.193)$ & $(0.109)$ & $(0.180)$ \\
Frequency & $-0.706^{* * *}$ & $0.706^{* * *}$ & $-0.830^{* * *}$ & $0.830^{* * *}$ & $-0.841^{* * *}$ & $0.841^{* * *}$ \\
& $(0.046)$ & $(0.046)$ & $(0.082)$ & $(0.082)$ & $(0.073)$ & $(0.073)$ \\
Duration & $-1.386^{* * *}$ & $1.386^{* * *}$ & $-1.704^{* * *}$ & $1.704^{* * *}$ & $-1.724^{* * *}$ & $1.724^{* * *}$ \\
& $(0.092)$ & $(0.092)$ & $(0.158)$ & $(0.158)$ & $(0.141)$ & $(0.141)$ \\
Cost & $-7.1842^{* * *}$ & $7.1842^{* * *}$ & $-6.484^{* * *}$ & $6.484^{* * *}$ & $-7.418^{* * *}$ & $7.418^{* * *}$ \\
& $(0.531)$ & $(0.531)$ & $(0.801)$ & $(0.801)$ & $(0.750)$ & $(0.750)$ \\
\hline Log-likelihood & -1383.365 & & -663.413 & & -780.223 & \\
Pseudo $R^{2}$ & 0.27 & & 0.35 & & 0.37 & \\
Observations & 1,736 & & 932 & & 1,120 & \\
Subjects & 434 & & 233 & & 280 &
\end{tabular}

Note: Standard errors in parentheses. $* * *, * *, *$ denote significance at $1 \%, 5 \%$, and $10 \%$ levels, respectively. 
Table B6. Random parameter logit model for different sectors

\begin{tabular}{|c|c|c|c|c|c|c|c|c|c|c|}
\hline \multirow{2}{*}{ Variable } & \multicolumn{2}{|c|}{ Food } & \multicolumn{2}{|c|}{ Textile } & \multicolumn{2}{|l|}{ Metal } & \multicolumn{2}{|c|}{ Nonmetal } & \multicolumn{2}{|c|}{ Plastic } \\
\hline & Coeff. & Std. dev. & Coeff. & Std. dev. & Coeff. & Std. dev. & Coeff. & Std. dev. & Coeff. & Std. dev. \\
\hline \multirow[t]{2}{*}{ ASC } & -0.019 & $0.709^{* * *}$ & -0.088 & 0.642 & 0.077 & $0.721^{* * * *}$ & 0.071 & 0.537 & 0.113 & $0.853^{* * *}$ \\
\hline & $(0.130)$ & $(0.224)$ & $(0.119)$ & $(0.207)$ & $(0.101)$ & $(0.172)$ & $(0.164)$ & $(0.353)$ & $(0.126)$ & $(0.190)$ \\
\hline \multirow{2}{*}{ Frequency } & $-0.743^{* * *}$ & $-0.743^{* * *}$ & $-0.635^{* * *}$ & $-0.635^{* * *}$ & $-0.791^{* * *}$ & $-0.791^{* * *}$ & $-1.012^{* * *}$ & $-1.012 * * *$ & $-0.801^{* * *}$ & $-0.801^{* * *}$ \\
\hline & $(0.084)$ & $(0.084)$ & $(0.067)$ & $(0.067)$ & $(0.067)$ & $(0.067)$ & $(0.140)$ & $(0.140)$ & $(0.076)$ & $(0.076)$ \\
\hline \multirow[t]{2}{*}{ Duration } & $-1.471^{* * *}$ & $-1.471^{* * *}$ & $-1.221^{* * *}$ & $-1.221^{* * * *}$ & $-1.750^{* * *}$ & $-1.750^{* * * *}$ & $-1.951^{* * *}$ & $-1.951 * * *$ & $-1.496^{* * * *}$ & $-1.496^{* * *}$ \\
\hline & $(0.168)$ & $(0.168)$ & $(0.132)$ & $(0.132)$ & $(0.141)$ & $(0.141)$ & $(0.263)$ & $(0.263)$ & $(0.146)$ & $(0.146)$ \\
\hline \multirow[t]{2}{*}{ Cost } & $-8.909^{* * *}$ & $-8.909^{* * * *}$ & $-5.760^{* * *}$ & $-5.760^{* * * *}$ & $-7.189^{* * *}$ & $-7.189^{* * *}$ & $-7.466^{* * *}$ & $-7.466 * * *$ & $-6.671^{* * * *}$ & $-6.671^{* * *}$ \\
\hline & $(1.075)$ & $(1.075)$ & $(0.732)$ & $(0.732)$ & $(0.715)$ & $(0.715)$ & $(1.249)$ & (1.249) & $(0.769)$ & $(0.769)$ \\
\hline Log-likelihood & -534.80 & & -534.23 & & -886.82 & & -294.46 & & -572.65 & \\
\hline Pseudo $R^{2}$ & 0.26 & & 0.27 & & 0.33 & & 0.42 & & 0.35 & \\
\hline Observations & 656 & & 664 & & 1,212 & & 460 & & 796 & \\
\hline Subjects & 164 & & 166 & & 303 & & 115 & & 199 & \\
\hline
\end{tabular}

Note: Standard errors in parentheses. $* * *, * *, *$ denote significance at $1 \%, 5 \%$, and $10 \%$ levels, respectively. 


\section{References}

Allcott, H., A. Collard-Wexler, and S. D. O’Connell. 2016. "How Do Electricity Shortages Affect Industry? Evidence from India.” American Economic Review 106: 587-624.

Andersen, T. B., and C.-J. Dalgaard. 2013. "Power Outages and Economic Growth in Africa." Energy Economics 38: 19-23.

Beenstock, M. 1991. “Generators and the Cost of Electricity Outages.” Energy Economics 13: 283-89.

Carlsson, F., M. Kataria, and E. Lampi. 2010. "Dealing with Ignored Attributes in Choice Experiments on Valuation of Sweden's Environmental Quality Objectives." Environmental and Resource Economics 47: 65-89.

Carlsson, F., and P. Martinsson. 2007. "Willingness to Pay among Swedish Households to Avoid Power Outages: A Random Parameter Tobit Model Approach.” Energy Journal 28: 75-89.

_ 2008. "Does It Matter When a Power Outage Occurs? A Choice Experiment Study on the Willingness to Pay to Avoid Power Outages.” Energy Economics 30: 1232-45.

Carlsson F., Martinsson P., Akay A. 2011. The effect of power outages and cheap talk on willingness to pay to reduce outages, Energy Economics 33, 790-798

Collier, P., and A. J. Venables. 2012. "Greening Africa? Technologies, Endowments and the Latecomer Effect.” Energy Economics 34: S75-S84.

Cummings, R. G., and L. O. Taylor. 1999. "Unbiased Value Estimates for Environmental Goods: A Cheap Talk Design for the Contingent Valuation Method." American Economic Review 89: 649-65.

Dinkelman, T. 2011. “The Effects of Rural Electrification on Employment: New Evidence from South Africa." American Economic Review 101: 3078-3108.

Eifert, B., A. Gelb, and V. Ramachandran. 2008. "The Cost of Doing Business in Africa: Evidence from Enterprise Survey Data.” World Development 36: 1531-46.

Fisher-Vanden, K., E. T. Mansur, and Q. Wang. 2015. "Electricity shortages and Firm Productivity: Evidence from China's Industrial Firms." Journal of Development Economics 114: 172-88.

Foster, V., and J. Steinbuks. 2009. "Paying the Price for Unreliable Power Supplies: In-House Generation of Electricity by Firms in Africa." Policy Research Working Paper No. WPS 4913. Washington, DC: World Bank. 
Ghosh, R., Y. Goyal, J. Rommel, and J. Sagebiel. 2017. "Are Small Firms Willing to Pay for Improved Power Supply? Evidence from a Contingent Valuation Study in India.” Energy Policy 109: 659-65.

Hensher, D. A., and W. H. Greene. 2003. "The Mixed Logit Model: The State of Practice." Transportation 30: 133-76.

Hensher, D. A., J. Rose, and W. H. Greene. 2005. "The Implications on Willingness to Pay of Respondents Ignoring Specific Attributes.” Transportation 32: 203-22.

Lipscomb, M., M. A. Mobarak, and T. Barham. 2013. "Development Effects of Electrification: Evidence from the Topographic Placement of Hydropower Plants in Brazil.” American Economic Journal: Applied Economics 5: 200-231.

Meles, T. H. 2017. Power Outages, Increasing Block Tariffs and Billing Knowledge. Sweden: University of Gothenburg.

Moeltner, K., and D. F. Layton. 2002. “A Censored Random Coefficients Model for Pooled Survey Data with Application to the Estimation of Power Outage Costs." Review of Economics and Statistics 84: 552-61.

Morrison, M., and C. Nalder. 2009. "Willingness to Pay for Improved Quality of Electricity Supply across Business Type and Location.” Energy Journal 30: 117-33.

Oseni, M. O. 2017. “Self-Generation and Households' Willingness to Pay for Reliable Electricity Service in Nigeria.” Energy Journal 38: 165-94.

Ozbafli, A., and G. Jenkins. 2016. "Estimating the Willingness to Pay for Reliable Electricity Supply: A Choice Experiment Study." Energy Economics 56: 443-52.

Reinikka, R., and J. Svensson. 2002. "Coping with Poor Public Capital." Journal of Development Economics 69: 51-69.

Scarpa, R., T. J. Gilbride, D. Campbell, and D. A. Hensher. 2009. "Modelling Attribute Nonattendance in Choice Experiments for Rural Landscape Valuation." European Review of Agricultural Economics 36: 151-74.

Scarpa, R., R. Zanoli, V. Bruschi, and S. Naspetti. 2012. "Inferred and Stated Attribute Nonattendance in Food Choice Experiments." American Journal of Agricultural Economics 95: 165-80. 